\title{
Simulation and Optimization of Pressure-Swing Distillation System for High Purity Acetonitrile
}

\author{
Feini Huang, Shu Zheng, Yuxuan Chen, Mengxiang Zhou and Xiaofang Sun ${ }^{*}$ \\ College of Chemical Engineering, Zhejiang University of Technology, Zhejiang Hangzhou 310014, China \\ *Corresponding author
}

\begin{abstract}
According to the feature that composition of the azeotrope could be changed with the change of pressure, the method of pressure-swing distillation was applied to separate the azeotrope of acetonitrile-water and obtain high purity acetonitrile. A simulation model of pressure-swing distillation system was established by chemical engineering software Aspen Plus to get initial results. Meanwhile, the influence of process parameters such as reflux ratio, feed stage, tower pressure and distillate flow rate on the rectification effect was analyzed by the model analysis tools. Ultimately, the optimization model of minimal energy consumption of distillation process was established under the premise assuring the quality of products to obtain energy-efficient optimizing operation parameters. The results showed that the simulation met technology requirements,

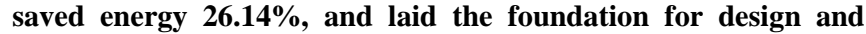
implementation of real-time optimization control system.
\end{abstract}

Keywords-acetonitrile; pressure-swing distillation; simulation; optimization

\section{INTRODUCTION}

Acetonitrile is a kind of organic solvent with high performance widely used in pharmacy, chemical engineering and other fields. Some special techniques should be used to obtain the high purity acetonitrile while water and acetonitrile are apt to form an azeotrope. At present, the main methods to separate acetonitrile from the acetonitrile-water azeotrope are pressure-swing distillation, azeotropic distillation, salt fractionation, dehydration, extractive distillation, interval salting extractive distillation. In petrochemical industry, according to the feature that composition of the azeotrope could be changed with the change of pressure, the method of pressure-swing distillation was usually applied to separate the azeotrope of acetonitrile-water and obtain high purity acetonitrile $^{[1,4]}$.

Aspen Plus is a large-scale chemical engineering process software, based on steady state chemical engineering simulation, optimization, sensitivity analysis and economic evaluation, providing a set of intact unit operation model, and used for various operation process. From single operation to the whole process simulation, it also is the only complex process simulation system in the world that can solve problems of complicated materials like solid, electrolyte, biomass, routine materials and the like. Its applications in calculation of phase equilibrium and distillation of multiple towers give expression to the important development of modern process technology development level [5, 7].
Pressure-swing distillation process of acetonitrile-water was simulated by Aspen Plus process simulation software in this study, whose sensitivity analysis tool was used to analyst the influence of operating parameters to production. Meanwhile, the optimization model of minimal energy consumption of distillation process was established and the best operating parameters were obtained, which has an important guiding significance to the experiment.

\section{Process ANd SePARATION PRINCIPLE OF PRESSURE- SWING DISTILLATION}

\section{A. Separation Principle}

As we know, the mass composition of acetonitrile-water azeotrope is $84 \%$ acetonitrile and its azeotropic point is $77^{\circ} \mathrm{C}$ under atmospheric pressure. According to the composition curves (FIGURE I \& FIGURE II) of acetonitrile in the azeotrope of acetonitrile-water under different pressure, at $0.4 \mathrm{bar}$, the mass fraction of acetonitrile is 0.87 , and at 3.5bar, it becomes 0.76 . On the basis of the feature that composition of the azeotrope could be changed with the change of pressure, the method of pressure-swing distillation could be used to obtain the high purity acetonitrile.

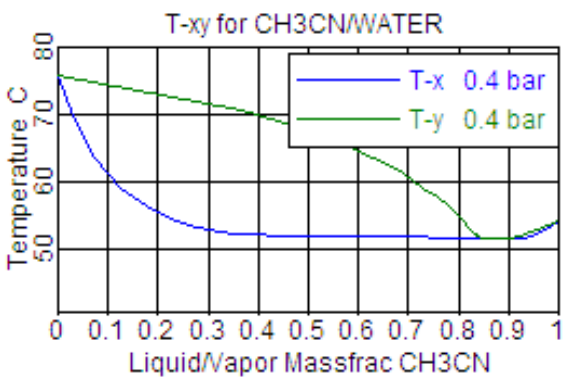

FIGURE I. P=0.4BAR, T-X-Y CURVE OF ACETONITRILE-WATER AZEOTROPE

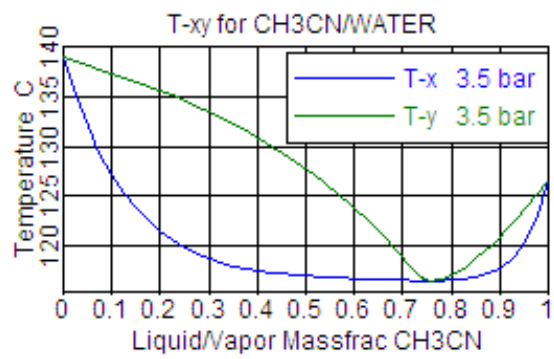

FIGURE II. P=3.5BAR, T-X-Y CURVE OF ACETONITRILE-WATER AZEOTROPE 


\section{B. Process Description}

The FIGURE III shows the process of pressure-swing distillation that consists of vacuum tower (B1) and pressurized rectifying tower (B2) under different operating pressure. PUMP is a booster pump connecting the vacuum tower and the pressurized tower, 1-RAW-IN is raw stream, 3-REC-O is the circular stream, 2-WAT-O is the stream from vacuum tower kettle (waste water), and 6-PROD-O is the final product acetonitrile stream.

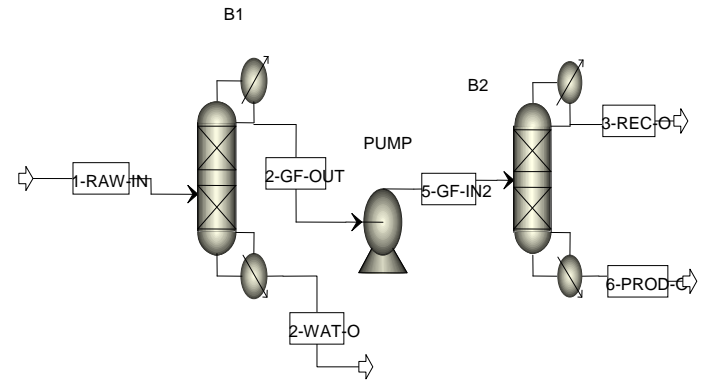

FIGURE III. THE FLOW DIAGRAM OF ACETONITRILE-WATER PRESSURE-SWING DISTILLATION PROCESS

In which, acetonitrile-water stream (1-RAW-IN) and the liquid phase stream (3-REC-O) from the top of the pressurized tower needed to separate ulteriorly were mixed up and got access to Tower B1, where stream (2-WAT-O) from the bottom was mostly water, and the stream (2-GF-OUT) was the acetonitrile-water azeotrope, which turned to stream (5-GF-IN2) and as the feed of pressurized tower by the booster pump (PUMP), thus, the stream (6-PRO-O) was obtained from the bottom of pressure tower was the high purity acetonitrile.

\section{SYSTEM SIMULATION}

\section{A. Physical Property Model}

The key to simulation is choosing the proper physical property model. Aspen Plus has a set of complete physical property models based on state equation and activity coefficient NRTL model $[8,9]$ was chosen and used to calculate vaporliquid phase equilibrium of acetonitrile-water azeotrope in this study, which showed a good data consistency with literature.

\section{B. Process Requirements}

In accordance with the separation results, the feed composition was approximately 50\% acetonitrile and 50\% water (mass fraction), quantity of flow was $100 \mathrm{Kg} / \mathrm{h}$. According to the actual production, the mass fraction of water in the azeotrope from the top of vacuum tower should be controlled less than $13 \%$, and the mass fraction of water from the top of pressure tower should be more than $24 \%$. Thus, the high purity acetonitrile (99.9\%) could be obtained from the bottom of pressurized tower, and the mass fraction of water could be less than 50ppm.

\section{Simulation Calculation}

The initial simulation was carried out with parameters as the TABLE I. Then, the pressure-swing distillation process was calculated by NRTL model and Radfrac modules, whose results as TABLE II. The purity of product acetonitrile was over $99.9 \%$ and water fraction was less than $50 \mathrm{ppm}$, which was satisfied the separation requirement. However, the reboilers and condensers of the two towers were of high duty. So, on the basis of separating effect, energy reduction was needed and the initial operating parameters should be optimized.

TABLE I. THE INITIAL PARAMETERS OF DISTILLATION TOWERS

\begin{tabular}{|c|c|c|c|c|}
\hline \multirow{2}{*}{ Column } & \multicolumn{4}{|c|}{ The initial parameters of distillation towers } \\
\cline { 2 - 5 } & $\begin{array}{c}\text { Reflux } \\
\text { ratio }\end{array}$ & $\begin{array}{c}\text { Temperature } \\
\left({ }^{\circ} \mathrm{C}\right)\end{array}$ & $\begin{array}{c}\text { Feed } \\
\text { position }\end{array}$ & $\begin{array}{c}\text { Total } \\
\text { stages }\end{array}$ \\
\hline Vacuum tower & 2.0 & 0.5 & 14 & 20 \\
\hline $\begin{array}{c}\text { Pressurized } \\
\text { tower }\end{array}$ & 3.0 & 3.5 & 14 & 20 \\
\hline
\end{tabular}

TABLE II. THE INITIAL OPTIMIZED RESULTS OF DISTILLATION TOWERS

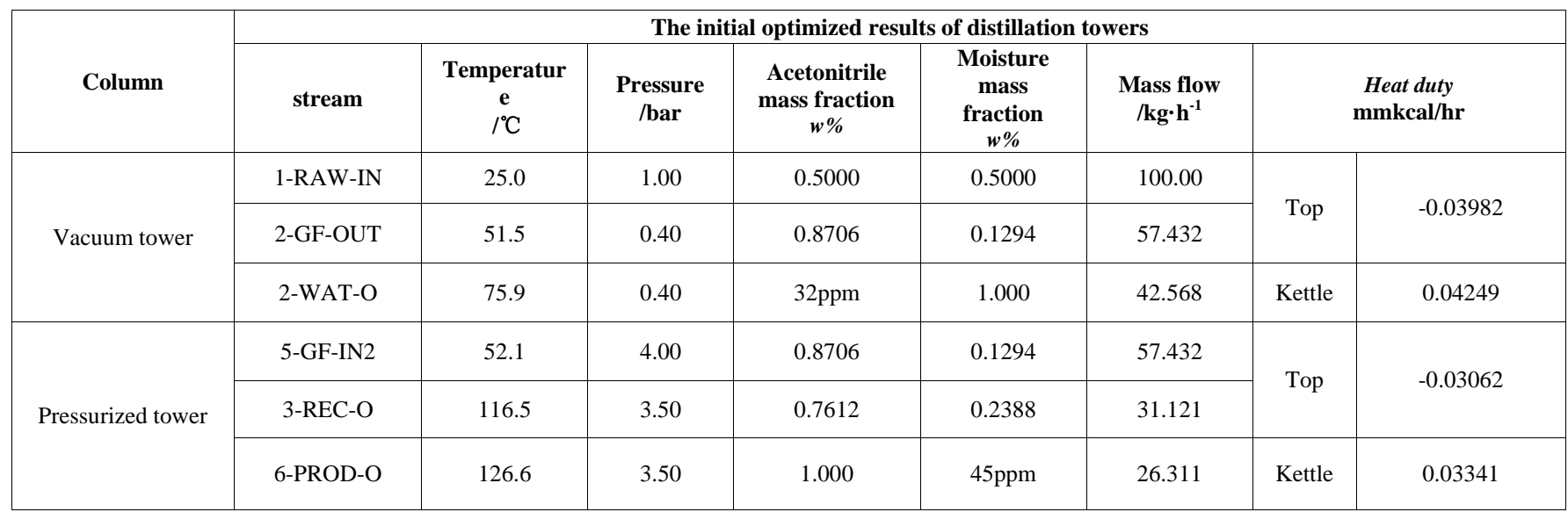




\section{SENSITIVITY ANALYSIS}

\section{A. Sensitivity Analysis of Vacuum Tower}

Where, the influence of process parameters such as reflux ratio-R, feed stage-NF, tower pressure-P and distillate flow rate- $\mathrm{D}$ on the rectification effect of vacuum tower was analyzed by the model analysis tools. Sensitivity analysis of R is shown in FIGURE IV, NF is shown in FIGURE V, $\mathrm{P}$ is shown in FIGURE VI, and D is shown in FIGURE VII. Results showed that the $\mathrm{R}$ should be more than 1.6, the NF should be in the range of 14 to 17 , the $\mathrm{P}$ should be less than $0.4 \mathrm{bar}$, and the $\mathrm{D}$ should be less than $57 \mathrm{~kg} / \mathrm{hr}$.

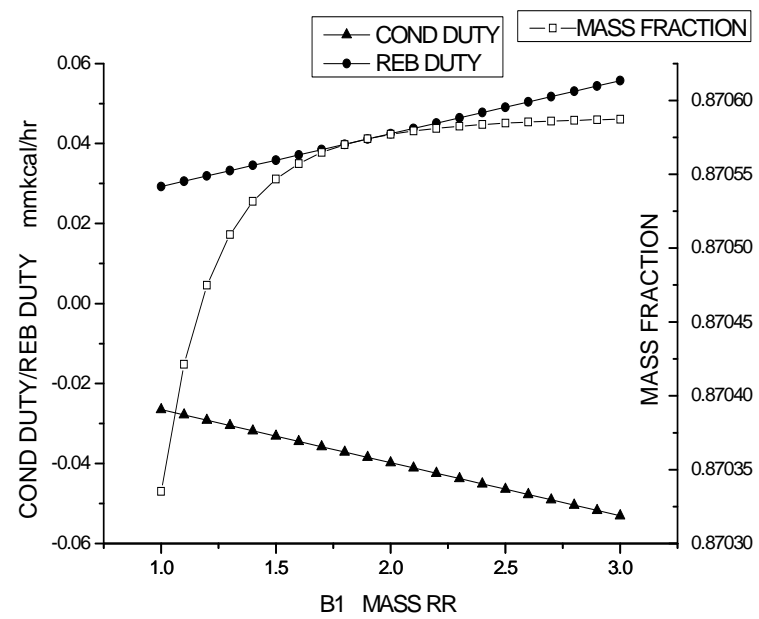

FIGURE IV. THE EFFECT OF REFLUX RATIO ON MASS FRACTION OF ACETONITRILE, HEAT DUTY OF REBOILER AND CONDENSER IN VACUUM TOWER

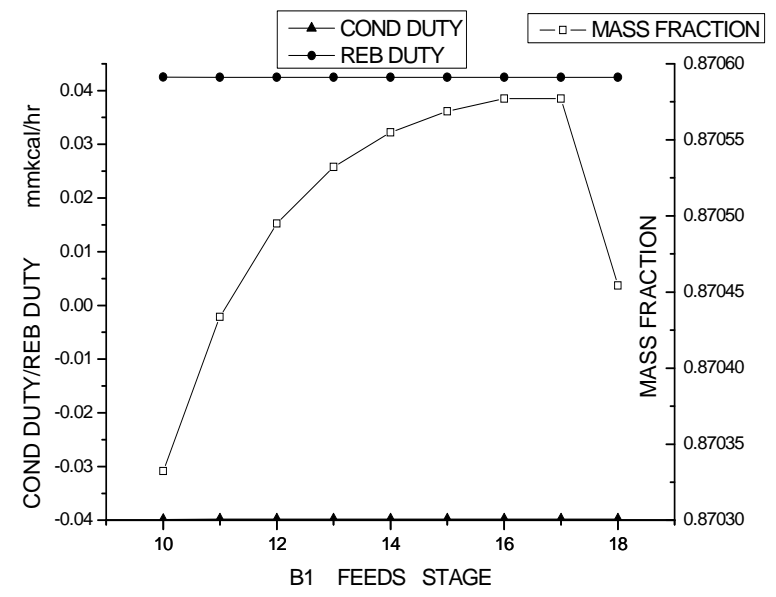

FIGURE V. THE EFFECT OF FEED STAGE ON MASS FRACTION OF ACETONITRILE , HEAT DUTY OF REBOILER AND CONDENSER IN VACUUM TOWER

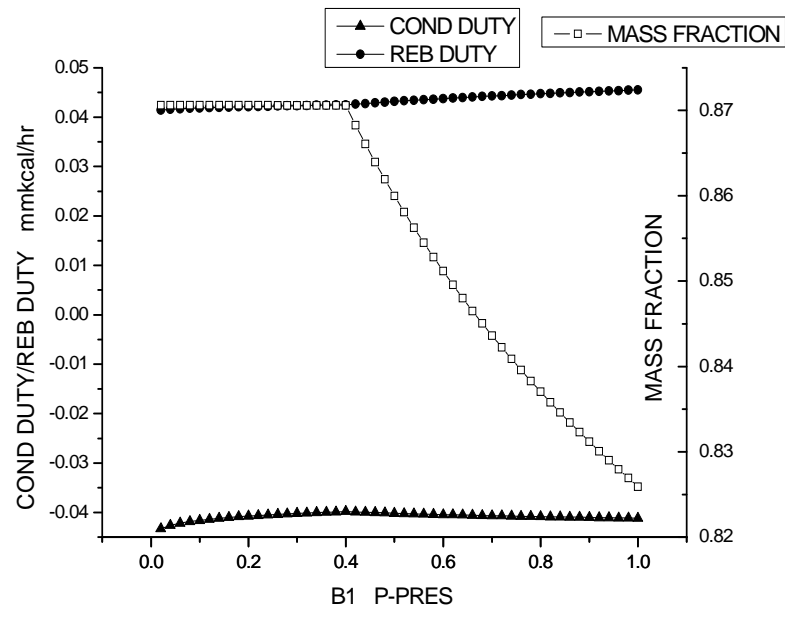

FIGURE VI. THE EFFECT OF TOWER PRESSURE ON MASS FRACTION OF ACETONITRILE, HEAT DUTY OF REBOILER AND CONDENSER IN VACUUM TOWER

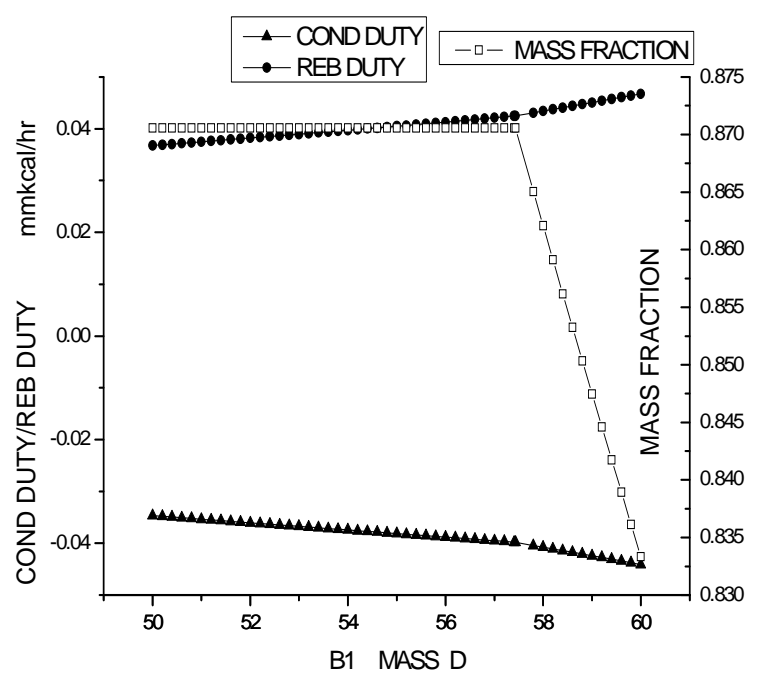

FIGURE VII. THE EFFECT OF DISTILLATE FLOW RATE ON MASS FRACTION OF ACETONITRILE, HEAT DUTY OF REBOILER AND CONDENSER IN VACUUM TOWER

\section{B. Sensitivity Analysis of Pressurized Tower}

In which, the influence of reflux ratio- $\mathrm{R}$, feed stage-NF, and tower pressure-P on the rectification effect of pressurized tower was analyzed as follows. Sensitivity analysis of $\mathrm{R}$ is shown in FIGURE VIII, NF is shown in FIGURE IX, and the P is shown in FIGURE X. Results showed that the R should be more than 0.5 , the NF should be in the range of 12 to 16 , and the P should be more than 3.5 bar. 


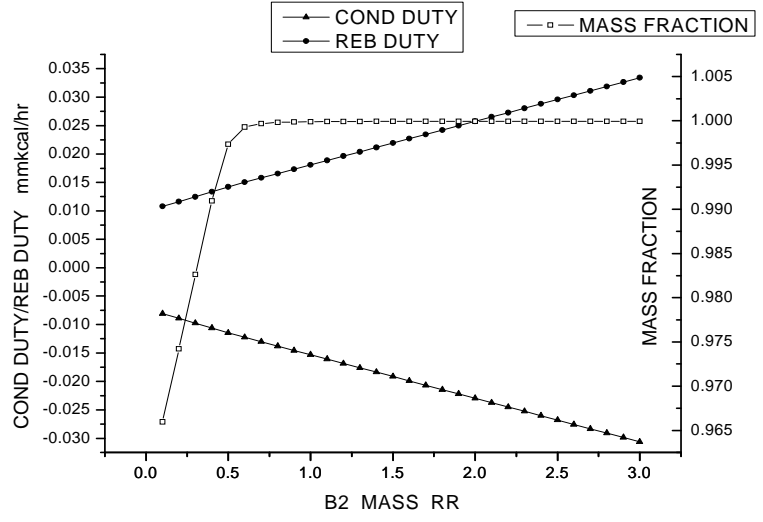

FIGURE VIII. THE EFFECT OF REFLUX RATIO ON MASS FRACTION OF ACETONITRILE, HEAT DUTY OF REBOILER AND CONDENSER IN PRESSURIZED TOWER

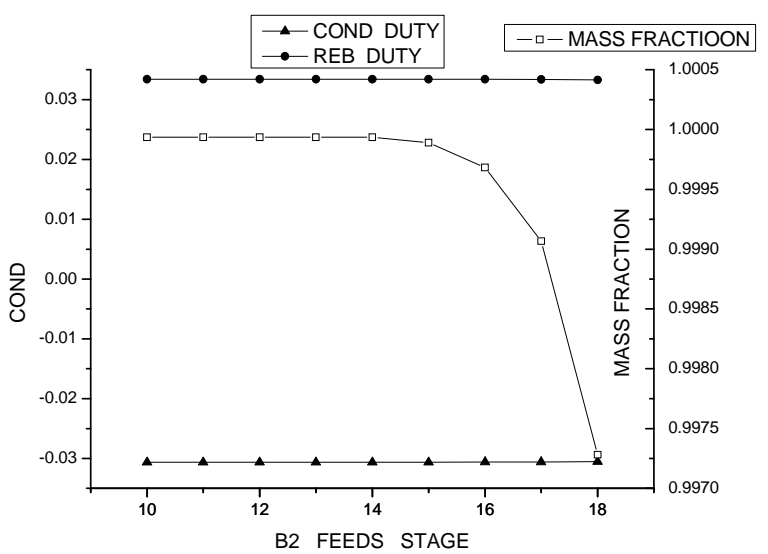

FIGURE IX. THE EFFECT OF FEED STAGE ON MASS FRACTION OF ACETONITRILE, HEAT DUTY OF REBOILER AND CONDENSER IN PRESSURIZED TOWER

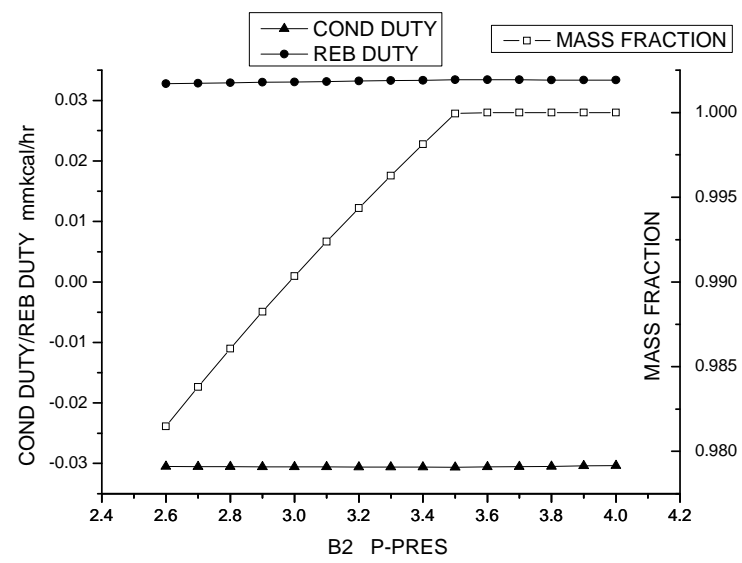

FIGURE X. THE EFFECT OF TOWER PRESSURE ON MASS FRACTION OF ACETONITRILE, HEAT DUTY OF REBOILER AND CONDENSER IN PRESSURIZED TOWER

\section{OPTIMIZATION MODEL}

\section{A. Establish an Optimization Model}

According to the features of pressure-swing distillation system, the optimization model of minimal energy consumption of distillation process was established under the premise assuring the quality of products to obtain energyefficient optimizing operation parameters.

In which, the stage number of two towers were changeless, and the target function (Minimum total heat duty), constraint condition, control variables were as follows:

Target function:

$$
\mathrm{Y}=\min (\mathrm{B} 1 \mathrm{REB}-\mathrm{B} 1 \mathrm{COND}+\mathrm{B} 2 \mathrm{REB}-\mathrm{B} 2 \mathrm{COND})
$$

Constraint condition:

$$
\mathrm{w}(\mathrm{CH} 3 \mathrm{CN}) \geqslant 0.999
$$

Control variables:

1) Vacuum tower:

$\mathrm{R}: 0.1 \leqslant \mathrm{R} \leqslant 3.0$;

NF: $14 \leqslant \mathrm{NF} \leqslant 17$;

$\mathrm{P}$ (bar): $0.0 \leqslant \mathrm{P} \leqslant 0.4$;

$\mathrm{D}\left(\mathrm{kg} \cdot \mathrm{h}^{-1}\right): 50 \leqslant \mathrm{D} \leqslant 60$

2) Pressurized tower:

$$
\begin{aligned}
& \mathrm{R}: 0.1 \leqslant \mathrm{R} \leqslant 3.0 ; \\
& \mathrm{NF}: 12 \leqslant \mathrm{NF} \leqslant 16 ; \\
& \mathrm{P}(\text { bar }): 3.0 \leqslant \mathrm{P} \leqslant 4.0
\end{aligned}
$$

\section{B. Results of Optimization}

Results of optimization were as follows: In vacuum tower: $\mathrm{R}=2.0, \mathrm{P}=0.4 \mathrm{bar}, \mathrm{NF}=16, \mathrm{D}=57 \mathrm{~kg} / \mathrm{hr}$; in pressurized tower: the $\mathrm{R}=0.58, \mathrm{P}=3.5 \mathrm{bar}, \mathrm{NF}=12$.

At last, the simulation was carried out again with optimized parameters, the results were obtained as TABLE III. The total heat duty of pressure-swing distillation system was reduced from 0.14634 to 0.10925 (mmkcal/hr), saved energy $26.14 \%$, which showed that the optimization of process parameters reached the expected effect.

\section{CONCLUSION}

1) Aspen Plus simulation software was applied to establish the process model, and NRTL thermodynamics model and Radfrac distillation model were chosen and used to calculate the distillation process, the mass fraction of acetonitrile and water attained the separating demand through the simulation, as the consequence, the established model could be used to simulate the process of pressure-swing distillation.

2) The influence of process parameters such as reflux ratio$\mathrm{R}$, feed stage-NF, tower pressure-P and distillate flow rate-D on the rectification effect was analyzed by sensitivity analysis tools. The optimization model of minimal energy consumption of distillation process was established under the premise 
assuring the quality of products, and the energy-efficient optimizing operation parameters were obtained. Ultimately, the results show that energy loss decreased $26.14 \%$ by optimized operating parameters in the separation process, which laid the foundation for design and implementation of real-time optimization control system.

TABLE III. THE OPTIMIZED RESULTS OF DISTILLATION TOWERS

\begin{tabular}{|c|c|c|c|c|c|c|c|c|}
\hline \multirow[b]{2}{*}{ Column } & \multicolumn{8}{|c|}{ The optimized results of distillation towers } \\
\hline & \multirow{2}{*}{$\begin{array}{c}\text { stream } \\
\text { 1-RAW-IN }\end{array}$} & \multirow{2}{*}{$\begin{array}{c}\begin{array}{c}\text { Temperatur } \\
\text { e } \\
{ }^{\circ} \mathrm{C}\end{array} \\
25.0\end{array}$} & \multirow{2}{*}{$\begin{array}{c}\begin{array}{c}\text { Pressure } \\
\text { /bar }\end{array} \\
1.00\end{array}$} & \multirow{2}{*}{$\begin{array}{c}\begin{array}{c}\text { Acetonitrile } \\
\text { mass fraction } \\
\text { w\% }\end{array} \\
0.5000\end{array}$} & \multirow{2}{*}{$\begin{array}{c}\begin{array}{c}\text { Moisture mass } \\
\text { fraction } \\
\text { w\% }\end{array} \\
0.5000\end{array}$} & \multirow{2}{*}{$\begin{array}{c}\begin{array}{c}\text { Mass flow } \\
\mathbf{k g} \cdot \mathbf{h}^{-1}\end{array} \\
100.00\end{array}$} & \multicolumn{2}{|c|}{$\begin{array}{l}\text { Heat duty } \\
\text { mmkcal/hr }\end{array}$} \\
\hline \multirow{3}{*}{$\begin{array}{l}\text { Vacuum } \\
\text { tower }\end{array}$} & & & & & & & \multirow{2}{*}{ Top } & \multirow{2}{*}{-0.03982} \\
\hline & 2-GF-OUT & 51.5 & 0.40 & 0.8706 & 0.1294 & 57.432 & & \\
\hline & 2-WAT-O & 75.9 & 0.40 & 32ppm & 1.000 & 42.568 & Kettle & 0.04249 \\
\hline \multirow{3}{*}{$\begin{array}{l}\text { Pressurized } \\
\text { tower }\end{array}$} & 5-GF-IN2 & 52.1 & 4.00 & 0.8706 & 0.1294 & 57.432 & \multirow{2}{*}{ Top } & \multirow{2}{*}{-0.01150} \\
\hline & 3-REC-O & 116.5 & 3.50 & 0.7612 & 0.2388 & 31.121 & & \\
\hline & 6-PROD-O & 126.6 & 3.50 & 1.000 & 45ppm & 26.311 & Kettle & 0.01428 \\
\hline
\end{tabular}

3) According to the optimized results, it can be seen that the main way to save energy is reflux ratio under the premise of ensuring the quality of products, and other factors have less influence on the energy consumption.

\section{ACKNOWLEDGMENT}

The authors gratefully acknowledge financial support for this work from the Program of Application and Research of Public Welfare Technology of Zhejiang Province, China (2016C33008).

\section{REFERENCES}

[1] Li Zhongjie, "High-purity acetonitrile refining technology development and application,” Petrochemical Technology, 2001,30(10), pp.785788,2001

[2] Seader J D, Henley E J, Separation Process Principles, New York: Prentice Hall Press, 2002

[3] Yang Deming,Wang Xinbing. “Adopt double pressure distillation process to separate toluene - simulation of n-butyl alcohol" in Petrochemical Technology, 2009,38(10), pp. 1081-1084.

[4] Estela L, Juan B M, MaCruz B, "Separation of di-n-propyl ether and npropyl alcohol by extractive distillation and pressure-swing distillation: Computer simulation and economic optimization” Chem.Eng.Prog . 2011, 50(11-12),pp.1266-1274.

[5] Sun Lanyi., "Chemical engineering process simulation using Aspen Plus-Aspen Plus tutorial” Chemical Industry and Engineering Progress 2005,24(8),pp.935-937

[6] Sun Wei,Li Lin,Chen Xiaochun.”ASPEN PLUS fault dispute and the application of the parameter optimization in the industrial column”Chemical Industry and Engineering Progress,2005,24(8)

[7] pp.935-937

[8] Qu Yixin, Numerical simulation and software of chemical engineering, 2006

[9] Cui Xianbao,Li Yang, Feng Tianyang. "The extractive distillation separation salt acetonitrile - water system”, Petrochemical Technology, 2007,36(12),pp.1229-1233

[10] Green D W, Preey R H. Preey’s Chemical Engineers’ Handbook. New York, McGraw Hill Press,2002. 